\title{
Enhancement of Aqueous Emulsion and Foam Stability with Oppositely Charged Surfactant/Polyelectrolyte Mixed Systems
}

\author{
J.F. Argillier, S. Zeilinger and P. Roche \\ Institut français du pétrole, IFP, 1-4 avenue de Bois-Préau, 92852 Rueil-Malmaison Cedex - France \\ email: j-françois-argillier@ifp.fr
}

\begin{abstract}
Résumé - Amélioration de la stabilité d'émulsions ou de mousses aqueuses à l'aide de systèmes mixtes tensio-actif/polymère de charges opposées - Les propriétés émulsifiantes et moussantes de systèmes mixtes tensio-actif/polymère ont été étudiées. L'addition d'une faible concentration d'un polyélectrolyte de charge opposée au tensio-actif permet d'améliorer la stabilité d'une émulsion ou d'une mousse aqueuse, à des concentrations en tensio-actif très faibles, typiquement inférieures à la $\mathrm{CMC}$, ce qui correspond à des gammes de concentrations où le tensio-actif seul ne permet pas de stabiliser le système dispersé macroscopique. Cet effet s'explique par la co-adsorption de chaînes de polymères et de molécules de tensio-actifs à l'interface fluide/fluide et la formation d'un complexe polymère/tensio-actif possédant une forte activité interfaciale. La complexation entre les 2 espèces et, par conséquent, la stabilité de l'émulsion ou de la mousse peuvent être contrôlées en ajustant les interactions électrostatiques entre les deux espèces chargées. Des polymères amphotères peuvent être utilisés pour obtenir des systèmes ajustables, en permettant le contrôle de la stabilité d'émulsions ou de mousses par le $\mathrm{pH}$.
\end{abstract}

\footnotetext{
Abstract - Enhancement of Aqueous Emulsion and Foam Stability with Oppositely Charged Surfactant/Polyelectrolyte Mixed Systems - We have studied emulsifying and foaming properties of oppositely charged surfactant/polyelectrolyte mixed systems. We have shown that adding a small amount of oppositely charged polyelectrolyte to a ionic surfactant enhances the stability of emulsion and foams at very low surfactant concentration, typically below the $C M C$, in a range of concentration where the surfactant alone is usually not efficient for stabilizing macroscopic dispersed systems. This effect is explained by the co-adsorption of polymer and surfactant molecules at the fluidlfluid interface and formation of a highly surface active surfactant-polymer complex. Complexation and therefore emulsion and foam stability can be tuned by adjusting electrostatic attraction between the two charged species. Use of amphoteric polyampholyte can be used as $\mathrm{pH}$ switchable system for controling emulsion or foam stability.
} 


\section{INTRODUCTION}

Interactions between surfactants and polymers is an active field of research in colloid science. Surfactants and polymers are encountered in many industrial applications like biochemical, pharmaceutical, food, cosmetics, paints and coatings, oil\&gas, in particular for controling the stability and/or the rheological properties of colloidal systems like emulsions, foams or suspensions. From a formulation point of view it is very important to control interactions between polymers and surfactants to insure that at least they do not alter the macroscopic properties of the formulation. One can try to go further and look for positive synergies between theses two classes of additives to optimize the formulation in terms of performances or cost. This is what will be presented in this paper within the specific class of mixed systems composed of ionic surfactant and polyelectrolye of opposite charge.

Mixtures of polymers and surfactants of opposite charges have been the subjects of many theoretical studies, both in bulk and at interfaces: see for example reviews and books covering these different aspects [1-6]. Polyelectrolyte and surfactant of opposite charge can form hydrophobic complexes in bulk $[7,8]$ at a surfactant concentration called the Critical Aggregation Concentration (CAC) that is often much smaller than the Critical Micelle Concentration (CMC), due to the strong electrostatic interaction between the polyelectrolyte charged groups and the ionic polar heads of the surfactant. It has also been shown recently that in dilute aqueous solutions nanostructured complexes can be formed [9].

Interactions between oppositely charged polymer and surfactant also lead to the formation of interfacial mixed systems that have been shown to lower the surface tension. Different experimental techniques have been used to get a better understanding of the interfacial behavior of the mixed layer: surface tension [9, 10], ellipsometry [11-14], NMR [15], X-ray reflectivity [16], neutron reflectivity [17, 18], brewster angle microscopy [19], surface rheology [20], thin film balance [21]. Interfacial complexation depends on many parameters depending on the systems. Among these we can cite polymer and surfactant concentrations [22, 23], charges ratio between surfactant and polymer [13, 24], polymer rigidity [25], polymer molecular mass [11, 24], electrolytes content, $\mathrm{pH}$ for amphoteric species.

Although the important number of theoretical studies on interfacial properties, very few studies concerns application of the mixed systems to stabilize macroscopic systems like emulsion [26] or aqueous foams [3, 20, 27-29]. The objective of this paper is to show that theses interactions can be used for stabilizing emulsions or foams at very low concentration of surfactant. In this paper are gathered results of our work concerning the use of surfactant and polyelectrolyte to enhance stability of aqueous emulsions and foams that were carried out at IFP in the last 10 years. It is not intended to be as an exhaustive analysis of the interactions at the microscopic level, nor to be used for being predictive, but more as a observation of the macroscopic properties that we think can have advantageous usage in different fields of application.

Different mixed systems have been studied: anionic surfactants and cationic polyelectrolytes, cationic surfactants and anionic polyelectrolytes. Concerning polymers, both synthetic and natural polyelectrolytes have been looked at to check the validity of the concept. Among the different parameters that we have studied are the charges of the two species and their concentrations.

\section{EXPERIMENTAL PART}

\subsection{Chemicals}

The surfactant Dodecyl Trimethyl Ammonium Bromide (DoTAB) was supplied by Fluka and used as received. Sodium Dodecylsulfate (SDS) was supplied by Aldrich and used as received. Polyelectrolytes used in this study are synthetic copolymers of Acrylamide/Acrylic Acid (AM/AA), copolymers of Acrylamide and AMPS (AM/AMPS) and cationic polymers AM/ADC. The different polyelectrolytes were synthesized by SNF Floerger and used without purification except for surface tension measurents where they were ultrafiltrated on a cut off 20000 membrane (Spectrum). Note that the AM/AMPS copolymer is ionized in the whole $\mathrm{pH}$ range (pKa very low), whereas the charge of the AM/AA copolymer varies with $\mathrm{pH}$. The structure of the synthetic polymers are described in Figure 1. In one example a natural

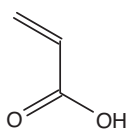

Acrylic Acid (AA)

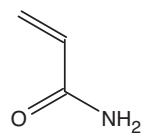

Acrylamide (AM)

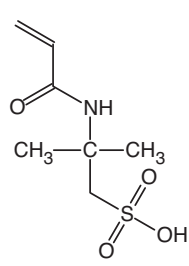

AMPS

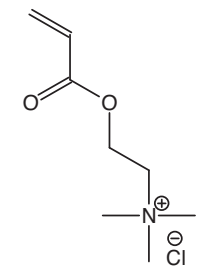

$\mathrm{ADC}$

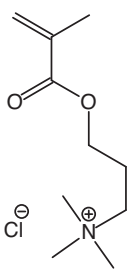

MAPTAC
AMPS: 2-Acrylamido-2-methyl-1-propanesulfonic acid

ADC: 2-(Dimethylamino)ethyl acrylate quaternized with Methyl chloride MAPTAC: 3-Trimethylammonium propyl methacrylamide chloride

Figure 1

Monomer structures. 


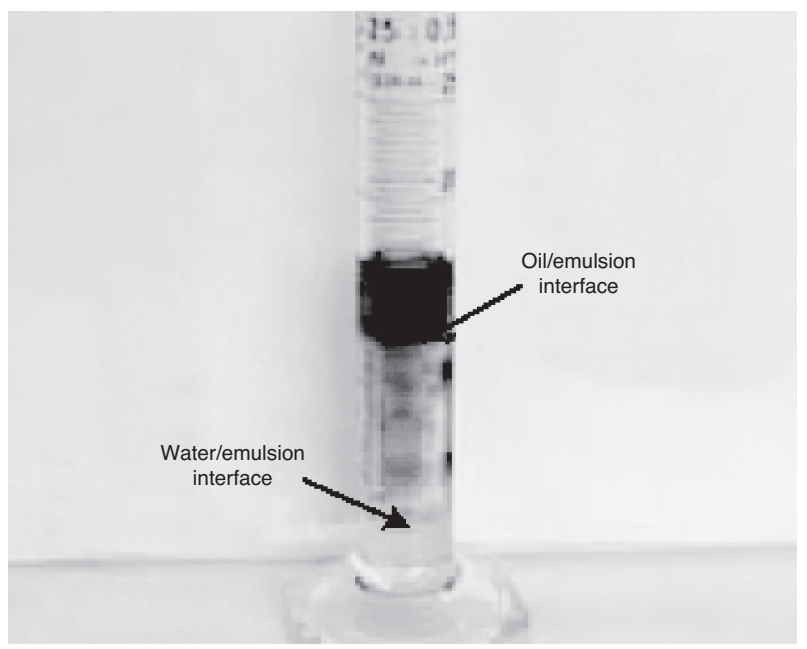

Figure 2

Destabilization of the oil in water emulsion: emulsion stability is measured by the half life time of resolved oil (after oil droplets coalescence) determined by following the oil/emulsion front.

anionic polymer (Arabic gum) obtained from the University of Rouen is used.

For all the experiments we used deionized water, that is distilled water purified with a four-stage reagent grade water system Milli-Q from Millipore. $\mathrm{KBr}$ and $\mathrm{NaCl}$ were supplied by Prolabo and Labosi, respectively. In most results the organic phase used is pure Dodecane. In one example rapeseed methyl ester is used.

\subsection{Emulsion Formation and Stability}

To make reliable measurements the emulsions were always made following the same procedure. The polymers were first dissolved in water and stirred overnight to ensure equilibrium of solvatation of the macromolecules. Then $60 \mathrm{~mL}$ of the solution was placed in a $200 \mathrm{~mL}$ becher and surfactant was added and the $\mathrm{pH}$ adjusted. $40 \mathrm{~mL}$ of dodecane is then added progressively under stirring using a Heidolph agitator with 3 pales coil at $800 \mathrm{rpm}$ for 20 minutes. Note that we did not see any significant change of droplets sizes whatever the systems used in this study.

Classical bottle tests are used to characterize the oil in water emulsion stability. A classical picture of the separation occurring as a function of time is shown of Figure 2, where we can see water at the bottom due to oil droplets creaming, the emulsion intermediate phase and free oil phase at the top obtained after coalescence of oil droplets. The stability of the emulsion will be characterized by following the front corresponding to the coalescence of the dispersed oil droplet and will be evaluated (Fig. 2) by the half life time of the resolved oil phase $T_{1 / 2}$ oil .

\subsection{Foam Formation and Drainage Test}

Foam is created by measuring $200 \mathrm{~g}$ of surfactant solution into a 3 liter glass beaker and agitating the solution for 2 minutes at 2000 RPM (agitator Janke and Kunkel). A 1\% SDS surfactant solution creates 2000 to $2200 \mathrm{~cm}^{3}$ foam. This corresponds roughly to a foam quality $\Gamma$ of $90 \%$. However, depending on the surfactant solution and its additives, the foaming capacity of the surfactant solution varies.

$$
\Gamma=\frac{V_{\text {gas }}}{V_{\text {total }}}=\frac{V_{\text {total }}-V_{\text {liquid }}}{V_{\text {total }}}
$$

where: $V_{\text {gas }}$ : Volume of gas

$V_{\text {liquid }}:$ Volume of surfactant solution

$V_{\text {total }}:$ Volume of gas plus volume of liquid

The foam is filled into a funnel which extends into a graded cylinder and the liquid drained from the foam is recorded as a function of time. The results are plotted as log $\frac{V_{0}-V}{V_{0}} v s$ time, where $V_{0}$ is the initial volume of surfactant solution and $V$ the liquid drained.

Figure 3 shows a typical measurement: One can distinguish three different periods during drainage: first, the early time period, I, just after the foam is filled into the funnel. The foam fills the vessel and the first liquid drains. The time measurement starts as the first liquid reaches the bottom of the cylinder. The drainage is initially slow, but accelerates after a few minutes. This is the foam drainage primarily due to gravity (II). The slope during this period is used to calculate foam stability. When most of the liquid has drained, drainage slows down and leads to the third characteristic time period (III), where foam drainage due to

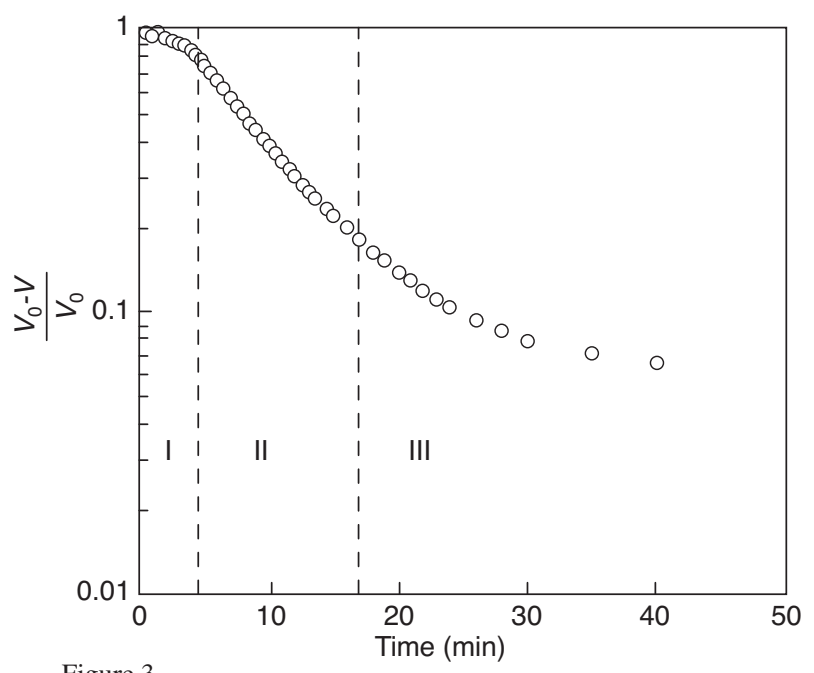

Figure 3

Foam drainage characterized by the evolution of the volume of foaming aqueous solution recovered as a function of time, after the foam being placed in a funnel. 
bubble coalescence and Ostwald ripening dominates. We do not use this slope for analysis, since it strongly depends on the initial bubble-size distribution. The duration of each period depends on the surfactant solution, whether additives slow drainage (polymers, electrolytes) or influence Ostwald ripening.

In region II, the drainage can be empirically approximated by the following expression:

$$
V=V_{0}(1-\exp (-k t))
$$

The foam drainage rate is the rate when half of the liquid has drained, from Equation (2) one finds:

$$
V D=\frac{k V_{0}}{2}
$$

\subsection{Viscosity Measurements}

To measure the viscosity of the aqueous solution (containing the mixed system: polyelectrolyte/surfactant or polyelectrolyte/simple salt), a Low-Shear 30 viscometer from Contraves was used with a coaxial cylindrical geometry. Apparent viscosities were measured between 1 and $50 \mathrm{~s}^{-1}$. In this range the viscosity appears to be constant (no shear thinning effect). The temperature was adjusted to $23.5^{\circ} \mathrm{C}$.

\subsection{Surface Tension}

To study the interfacial properties of the mixed systems, surface tensions were measured with a Du Nouy ring to limit polymer adsorption phenomena possible with a plate. A Kruss digital tensiometer K $10 \mathrm{ST}$ was used and the temperature was adjusted to $23.5 \pm 0.1{ }^{\circ} \mathrm{C}$. The value was calculated as the average of at least three measurements. It was recorded one night after the addition of surfactant to solutions of polymer so that equilibrium at the air water interface was reached.

\subsection{Turbidity}

To observe the onset of the formation of a surfactant/polyelectrolyte complex in bulk, transmittance of the aqueous solution was measured through turbidity measurement using a Turbiscan apparatus.

\section{RESULTS AND DISCUSSION}

\subsection{Emulsion with Mixed Systems}

\subsubsection{Effect of Surfactant Concentration}

Emulsions of dodecane in water are formed with the surfactant alone (DoTAB) and in presence of the anionic polymer (AM/AA) at $1000 \mathrm{ppm}$. $\mathrm{pH}$ is kept at 8 in all experiments. The stability of the emulsion is characterized by the half lifetime of dodecane $T_{1 / 2 \text { oil }}$. Comparison of the results are shown in Figure 4. The range of surfactant

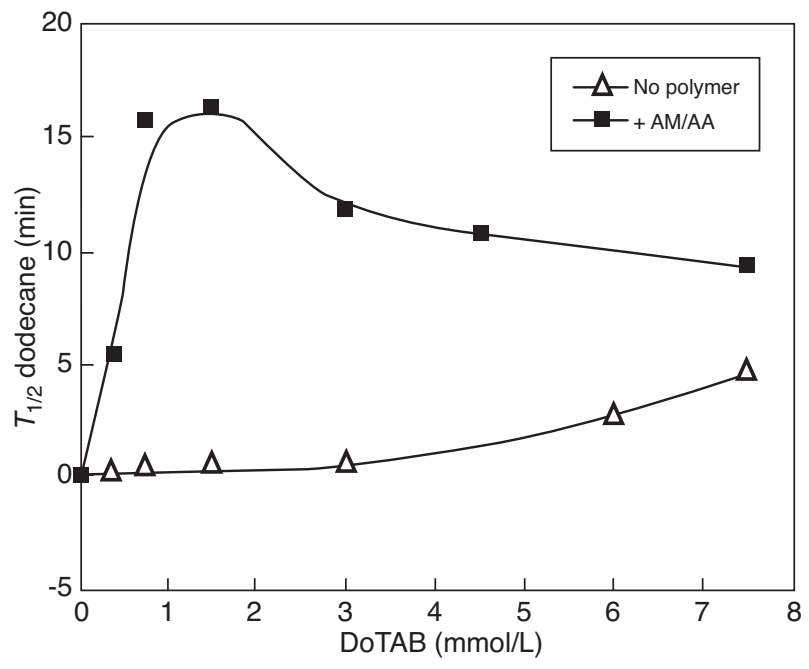

Figure 4

Comparative evolution of the half life time of the emulsion as a function of the surfactant DoTAB concentration for the surfactant alone or in presence of anionic polymer AM/AA.

concentration studied stays below the cmc of DoTAB (equal to $15 \mathrm{mmol} / \mathrm{L}$ in our conditions). For the surfactant alone, the emulsion is not stable below $4 \mathrm{mmol} / \mathrm{L}$, and only poorly stable $\left(T_{1 / 2 \text { oil }}=4.5 \mathrm{~min}\right.$ at $\left.\mathrm{CMC} / 2\right)$ as long as we stay below the cmc. In presence of the anionic AM/AA copolymer, we can see that the stability of the emulsion is enhanced. This enhancement is maximum at a concentration of surfactant close to $\mathrm{CMC} / 10$, i.e. $1.5 \mathrm{mmol} / \mathrm{L}$. The stabilization is more pronounced for cationic surfactant concentrations below $\mathrm{cmc} / 5(3 \mathrm{mmol} / \mathrm{L})$.

Note that this concentration range is below the onset of appreciable association in bulk as can be seen in Figure 5.

Let us note that in the same conditions, addition of a cationic polymer AM/ADC to the cationic surfactant DoTAB does not increase significantly the stability of emulsion.

Above $5 \mathrm{mmol} / \mathrm{L}$ of DoTAB the aqueous solution starts to become turbid (Fig. 5), that shows that cooperative surfactant/polymer complexation occurs in bulk at a macroscopic scale.

Interfacial tensions have been measured on a very close system (DoTAB/AM-AMPS 10\% charged copolymer) by Asnacios et al. [22]. They observed a lowering of the interfacial tension at DoTAB concentration lower than $5 \mathrm{~mol} / \mathrm{L}$, before an appreciable onset of association in bulk can be seen. This behavior has also been observed with different systems $[8,22,23]$. Lowering of the interfacial tension is the result of co-adsorption of AM/AA and DoTaB molecules at the oil/water interface and formation of a highly surface active surfactant-polymer complex. 


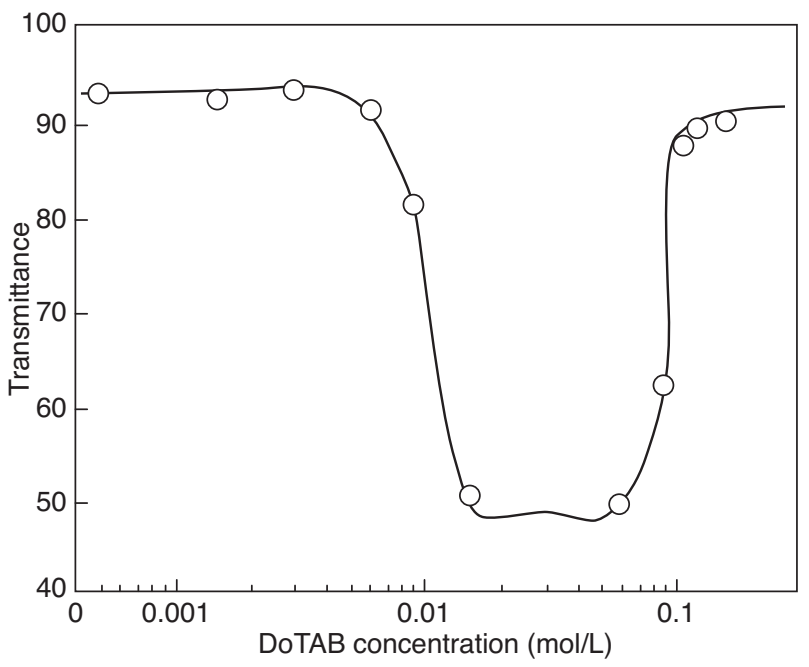

Figure 5

Bulk solution transmittance in presence of $1 \mathrm{~g} / \mathrm{L}$ of $\mathrm{AM} / \mathrm{AA}$ anionic polymer $(\mathrm{pH}=8)$ as a function of DoTAB concentration.

\subsubsection{Influence of pH: Switchable Interaction}

In this part we looked at the influence of $\mathrm{pH}$ on the stability of the aqueous emulsion with the same system DoTAB $\mathrm{AM} / \mathrm{AA}$. The concentration of DoTAB is fixed at $\mathrm{CMC} / 10$, i.e. $1.5 \mathrm{mmol} / \mathrm{L}$ and the concentration of AM/AA-90/10 fixed at $1000 \mathrm{ppm}$. In Figure 6 is represented the variation of the half life time $T_{1 / 2 \text { oil }}$ as a function of $\mathrm{pH}$. The results show that the emulsion is more stable at basic $\mathrm{pH}(\mathrm{pH}>6.5)$ than at acidic $\mathrm{pH}(\mathrm{pH}<5)$. Theses effects are related to the ionization of the acrylic groups that occurs for $\mathrm{pH}$ above $\mathrm{pKa}$. At high $\mathrm{pH}$, carboxylic groups are ionized and an interfacial complex is formed between surfactant molecules and polyelectrolytes through electrostatic attraction. This complex stabilizes the emulsion. At low $\mathrm{pH}$, the polymer is almost not charged and does not interact with the surfactant. Because of the low concentration of surfactant used ( $<\mathrm{CMC}$ ), the surfactant alone is not able to stabilize the emulsion. This result shows how one can control the stability or the destabilization of an emulsion with the use of a polyampholyte/ionic surfactant by tuning the $\mathrm{pH}$ [23].

\subsubsection{Influence of the lonic Strength: Control of the Polyelectrolyte/Surfactant Interactions}

As the interaction between the ionic surfactant and the water soluble polyelectrolyte is mostly electrostatic driven, it is of course of great interest to study the influence of added electrolytes. The anionic polymer used here is AM/AA-80/20 at $1000 \mathrm{ppm}$ and $\mathrm{pH} 8$. Figure 7 shows the evolution of the stability of the aqueous emulsion evaluated by $T_{1 / 2 \text { oil }}$ for different concentrations of $\mathrm{NaCl}$, up to $1 \mathrm{~mol} / \mathrm{L}$. Results point

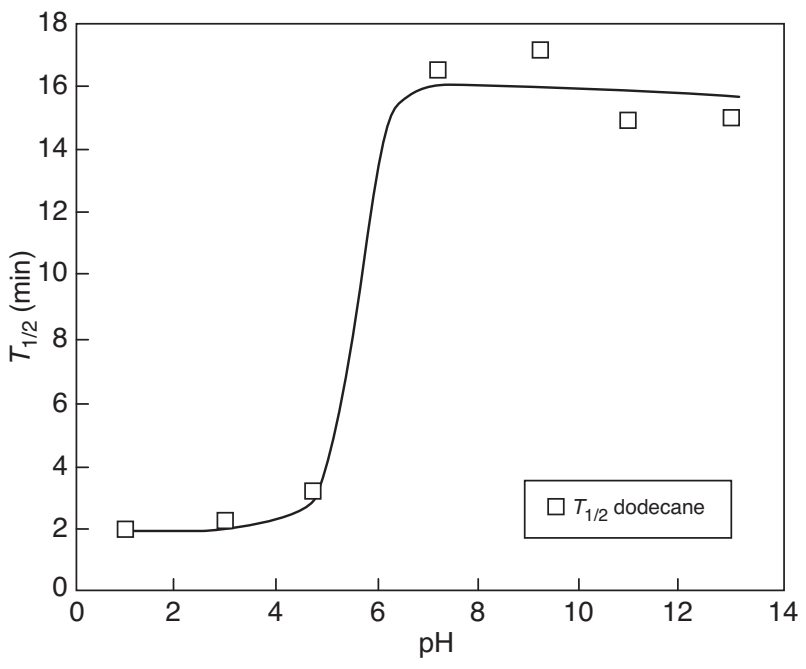

Figure 6

Influence of $\mathrm{pH}$ on emulsion stability for the DoTAB - AM/AA mixed system.

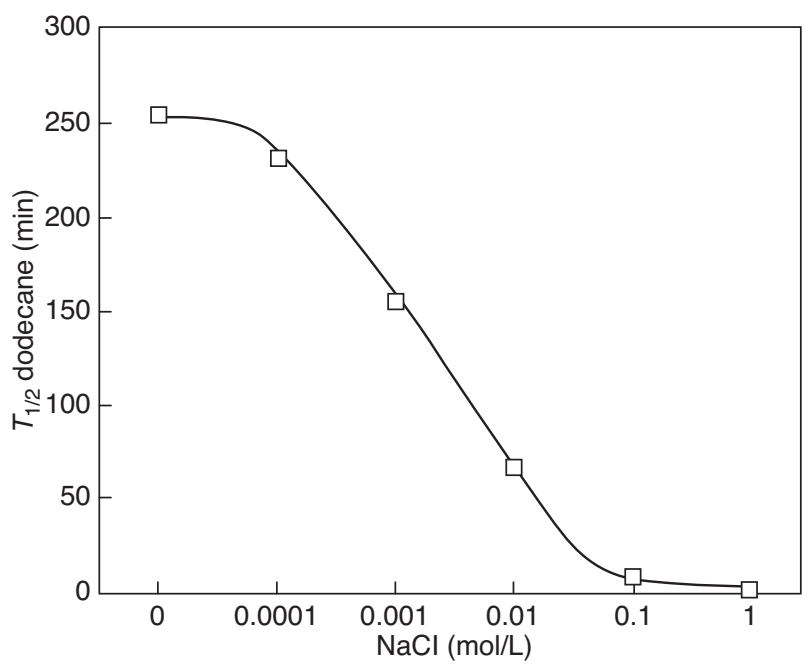

Figure 7

Influence of the ionic strength of emulsion stability (AM/AA-80/20 + DoTAB)

out that increasing the salt concentration decreases the stability of the emulsion. This sensitivity to the ionic strength was expected as increasing the ionic strength screens the electrostatic attraction between DoTAB and AM/AA and modifies strongly the complexation between the polyelectrolyte and the surfactant.

\subsubsection{Influence of the Charge Density of the Polyelectrolyte}

Table 1 compares the efficiency of 2 copolymers (AM/AA90/10) versus $\mathrm{AM} / \mathrm{AA}-80 / 20$ at $\mathrm{pH} 1$ and $\mathrm{pH}$ 8. DoTAB concentration is $1.5 \mathrm{mmol} / \mathrm{L}$, polymer concentration $1000 \mathrm{ppm}$. 
TABLE 1

\begin{tabular}{c|c|c}
\hline \multirow{2}{*}{ Polymer } & \multicolumn{2}{|c}{$T_{1 / 2 \text { oil }}(\min )$} \\
\cline { 2 - 3 } & $\mathrm{pH} 1$ & $\mathrm{pH} 8$ \\
\hline No polymer & $<0.5$ & $<0.5$ \\
\hline AM/AA-90/10 & 2 & 16 \\
\hline AM/AA-80/20 & 2 & 250 \\
\hline
\end{tabular}

As expected the charge density of the polyelectrolyte plays a key role in the efficiency of the emulsion stabilization at basic $\mathrm{pH}(8$ here) when the carboxylic groups are ionized. In acidic conditions, the polymer is not charged; there is no complexation and the emulsion is unstable. When charged, for the polymer molecular weight, emulsion stability enhancement is much more important for the $20 \%$ charged polymer. This is due to a more interfacialy active complex formation.

\subsubsection{Other Surfactant/Polymer Mixed Systems}

To check the validity of emulsion stability enhancement using electrostically mixed systems, different couples (surfactants/poyelectrolytes) and type of oils have been studied. For all systems, the same kind of behavior has been observed but the magnitude of the stability enhancement and the surfactant concentration range where it occurs vary from one system to another. It should be said at this point that we did not try to investigate further the reasons of these differences. It would need further studies that is beyond the scope of this paper. Clearly among the different parameters that should be taken into account, we can point out: polymer molecular weight, chain flexibility, degree of charge, nature of charge (carboxylate, sulfonate, etc.), nature of the surfactant (charge and nature, hydrophobic tail length, etc.), presence of electrolytes (type, valency, etc.).

In the following are gathered results obtained with different couples that confirmed the trend described so far. Results will be compared in terms of emulsion stability measured by $T_{1 / 2 \text { oil }}$.

TABLE 2

\begin{tabular}{c|c|c}
\hline \multirow{2}{*}{$\begin{array}{c}\text { DoTAB concentration } \\
(\mathrm{CMC}=15 \mathrm{mmol} / \mathrm{L})\end{array}$} & No Arabic gum & $2 \mathrm{~g} / \mathrm{L}$ of Arabic gum \\
\cline { 2 - 3 } & 0.6 & 1 \\
\hline 0 & 0.6 & 3.3 \\
\hline $2 / 1000$ & 0.6 & $>3$ days \\
\hline $5 / 1000$ & 0.6 & $>3$ days \\
\hline $1 / 100$ & 1.1 & $>3$ days \\
\hline $2 / 100$ & 56 & $>3$ days \\
\hline $1 / 10$ &
\end{tabular}

Vegetable oil (rapeseed methyl ester)/DOTAB/Arabic gum at $\mathrm{pH} 8$

Results given in Table 2 show a very significant increase of the emulsion life time in presence of the anionic biopolymer. The effect is very important even at very low surfactant concentration $(\mathrm{CMC} / 100)$.

With this natural polymer, very stable emulsions have been obtained even at very low surfactant concentration. Possible reason for such an effect comes from the nature of arabic gum which is a natural polymer that contain mixture of saccharides and glycoproteins.

Dodecane / DOTAB / copolymer AM/AMPS-80/20 pH 8

DoTAB concentration is $1.5 \mathrm{mmol} / \mathrm{L}$. With no polymer the $T_{1 / 2 \text { oil }}$ is below 0.6 minute, whereas in presence of $1 \mathrm{~g} / \mathrm{L}$ of AM/AMPS, $T_{1 / 2 \text { oil }}$ is around 160 minutes.

Opposite couple: negative surfactant, cationic polyelectrolyte: Dodecane / SDS / copolymer AM/ADC-90/10

Here we studied a anionic surfactant (SDS) with a cationic polymer (AM/ADC). Results of emulsion life time are gathered in Table 3. Here again, the presence of oppositely charged polymer induces a stabilization of the emulsion. Above 5/1000 of CMC of SDS, we can observe a stabilization of the emulsion for more than a week. Stabilizing effect is important, even for very low surfactant concentration.

TABLE 3

\begin{tabular}{c|c|c}
\hline \multirow{2}{*}{$\begin{array}{c}\text { SDS concentration } \\
(\mathrm{CMC}=8 \mathrm{mmol} / \mathrm{L})\end{array}$} & No AM/ADC & $0.5 \mathrm{~g} / \mathrm{L}$ of AM/ADC \\
\cline { 2 - 3 } & 0.5 & 1 \\
\hline 0 & 0.5 & 7 \\
\hline $1 / 1000$ & 0.5 & 300 \\
\hline $2.5 / 1000$ & 0.5 & $>9$ days \\
\hline $5 / 1000$ &
\end{tabular}

Very clearly a very strong interfacially active complex is formed between the SDS and the AM/ADC cationic copolymer.

\subsection{Foam}

In this part we describe the efficiency of mixed polyelectrolyte/surfactant system for increasing foaming properties. Results are expressed in terms of foamability (Foam Volume created within our experimental conditions, called FV) and stability (unstability characterized by the Drainage Velocity, called DV).

\subsubsection{SDS - AM/MAPTAC System}

As can be seen in Table 4, although the SDS concentration is rather small, small concentrations of cationic polymer in the solution enables foam formation and decreases foam drainage velocity (i.e. increases foam stability) as compared to a SDS surfactant solution without any polymer present. 
TABLE 4

\begin{tabular}{|c|c|c|c|c|c|}
\hline \multirow[t]{2}{*}{$\begin{array}{l}\text { SDS concentration } \\
(\mathrm{CMC}=6 \mathrm{mmol} / \mathrm{L})\end{array}$} & \multirow[t]{2}{*}{$\begin{array}{c}\text { SDS concentration } \\
(\mathrm{mmol} / \mathrm{L})\end{array}$} & \multicolumn{2}{|c|}{$\begin{array}{l}\text { Foam volume }(\mathrm{FV}) \\
(\mathrm{mL})\end{array}$} & \multicolumn{2}{|c|}{$\begin{array}{l}\text { Drainage velocity (DV) } \\
(\mathrm{mL} / \mathrm{min})\end{array}$} \\
\hline & & $\begin{array}{c}\text { No } \\
\text { polymer }\end{array}$ & $\begin{array}{c}750 \mathrm{ppm} \text { of } \\
\text { AM/MAPTAC-90/10 }\end{array}$ & $\begin{array}{c}\text { No } \\
\text { polymer }\end{array}$ & $\begin{array}{c}750 \mathrm{ppm} \text { of } \\
\text { AM/MAPTAC-90/10 }\end{array}$ \\
\hline $\mathrm{CMC} / 120$ & 0.05 & 0 & 500 & non measured & non measured \\
\hline $\mathrm{CMC} / 12$ & 0.5 & 500 & 600 & 22 & 5.4 \\
\hline $\mathrm{CMC} / 1.2$ & 5 & 1900 & 2200 & 18 & 5.1 \\
\hline
\end{tabular}

Note that the presence of small amounts of cationic polymer in a $5 \times 10^{-3} \mathrm{~mol} / \mathrm{L}$ SDS solution does not affect bulk viscosity significantly (0.9 mPa.s for SDS alone and $1.3 \mathrm{mPa} . \mathrm{s}$ for SDS and $750 \mathrm{ppm}$ of AM/MAPTAC-90/10).

As can been seen for the (SDS - AM/MAPTAC-90/10) in Table 5, low polymer concentration (200 ppm) allows to get stable foam. Increasing polymer concentration allows also reduce the foam drainage even more, but we observe that polymer solubility decreases as well.

TABLE 5

\begin{tabular}{c|c|c|c|c}
\hline $\begin{array}{c}\text { SDS } \\
(\mathrm{mmol} / \mathrm{L})\end{array}$ & $\begin{array}{c}\text { AM/MAPTAC-90/10 } \\
(\mathrm{ppm})\end{array}$ & $\begin{array}{c}\text { Drainage } \\
\text { rate } \\
(\mathrm{mL} / \mathrm{min})\end{array}$ & $\begin{array}{c}\text { Viscosity } \\
\text { at } 6 \mathrm{~s}^{-1} \\
(\mathrm{mPa} . \mathrm{s})\end{array}$ & $\begin{array}{c}\text { Foam } \\
\text { volume } \\
\left(\mathrm{cm}^{3}\right)\end{array}$ \\
\hline 5 & 0 & 18 & 0.9 & 1900 \\
\hline 5 & 200 & 7.6 & 1.2 & 2100 \\
\hline 5 & 400 & 6.0 & 1.2 & 2200 \\
\hline 5 & 750 & 5.1 & 1.3 & 2200 \\
\hline
\end{tabular}

Interfacial properties of mixed systems have been studied by many different authors with synthetic or natural polymers. Usually a Critical Aggregation Concentration CAC is observed below the CMC. We confirm this trend with our system. Here we will only show surface tension measurements that were conducted for a SDS solution alone and in presence of $300 \mathrm{ppm}$ of AM/MAPTAC (Fig. 8). The SDS curve shows no depression near the presumed CMC, the system appears free from impurities. Mixed solutions at $300 \mathrm{ppm}$ of AM/MAPTAC show a synergistic lowering of surface tension at very low surfactant concentration. The surface tension isotherm exhibits a plateau beginning at a critical aggregation concentration $(0.3 \mathrm{mmol} / \mathrm{L}$ in our case). At low surfactant concentration $\left(10^{-5} \mathrm{~mol} / \mathrm{L}\right.$ SDS), surface activity of the surfactant is negligible, yet there is a substantial lowering of the surface tension when the polymer is present. This suggests co-adsorption of AM/MAPTAC and SDS molecules at the air water interface and formation of a highly surface active surfactant-polymer complex (schematically depicted). Note that the cationic polymer alone in water does not lower the surface tension.

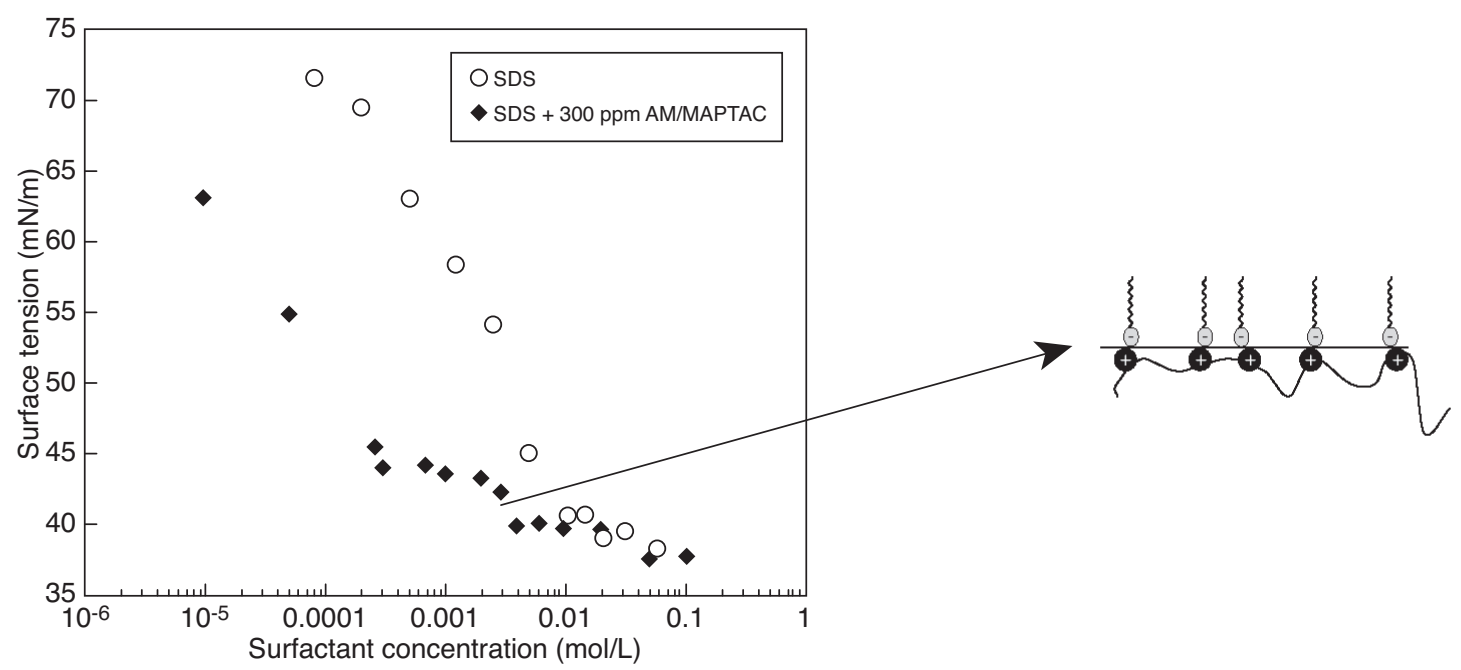

Figure 8

Effect of AM/MAPTAC on SDS surface tension curve. 
TABLE 6

\begin{tabular}{|c|c|c|c|c|c|}
\hline \multirow[t]{2}{*}{$\begin{array}{l}\text { DoTAB concentration } \\
(\mathrm{CMC}=15 \mathrm{mmol} / \mathrm{L})\end{array}$} & \multirow[t]{2}{*}{$\begin{array}{l}\text { DoTAB concentration } \\
(\mathrm{mmol} / \mathrm{L})\end{array}$} & \multicolumn{2}{|c|}{$\begin{array}{l}\text { Foam volume }(\mathrm{FV}) \\
\qquad(\mathrm{mL})\end{array}$} & \multicolumn{2}{|c|}{$\begin{array}{l}\text { Drainage velocity (DV) } \\
(\mathrm{mL} / \mathrm{min})\end{array}$} \\
\hline & & $\begin{array}{c}\text { No } \\
\text { polymer }\end{array}$ & $\begin{array}{c}750 \mathrm{ppm} \text { of } \\
\text { AM/MAPTAC-90/10 }\end{array}$ & $\begin{array}{c}\text { No } \\
\text { polymer }\end{array}$ & $\begin{array}{c}750 \mathrm{ppm} \text { of } \\
\text { AM/MAPTAC-90/10 }\end{array}$ \\
\hline $1 / 300$ & 0.05 & 0 & 500 & - & 5 \\
\hline $1 / 30$ & 0.5 & 0 & 600 & - & 5 \\
\hline $1 / 3$ & 5 & 1600 & 1700 & 40 & 9 \\
\hline
\end{tabular}

Besides static interfacial properties, data on interfacial rheology will certainly be of great interest.

\subsubsection{DoTAB - AM/AMPS System}

For the cationic surfactant/anionic polymer couple (DoTAB - AM/AMPS-90/10), results shown in Table 6 show also that addition of the anionic polymer enables to create foam and stabilize it in a range of low concentration where the surfactant alone is not efficient.

\section{CONCLUSIONS}

We have shown that adding a small amount of oppositely charged polyelectrolyte to a ionic surfactant enables to form and enhance the stability of emulsion and foam at very low concentration surfactant concentration (typically below the $\mathrm{CMC}$ ), in a range of concentration where the surfactant alone is usually not efficient for stabilizing macroscopic dispersed systems. This effect is explained by the co-adsorption of polymer and surfactant molecules at the fluid/fluid interface and formation of a highly surface active surfactant-polymer complex. Complexation and therefore emulsion and foam stability can be tuned by adjusting electrostatic attraction between the two charged species. Use of polyampholyte and/or amphoteric surfactant can be used as $\mathrm{pH}$ switchable system for controling emulsion/foam stabilization or destabilization depending on the desired application.

Note that with certain systems or conditions (highly charged polyelectrolyte, concentration of surfactant too high), the foam or the emulsion can become unstable. Interaction between polymer and surfactant are looked for but they should also be controlled carefully. Depending on the application, choice of proper system and optimization of formulation is necessary. Optimization can be done through a good understanding of the relationship between the chemistry and conformation of the 2 species, their microscopic interfacial interactions and the behavior of the macroscopic dispersed systems.

\section{ACKNOWLEDGEMENTS}

J.-F. Argillier would like to thank very warmly D. Langevin for stimulating discussions and also shared work on interfacial properties of these mixed systems over the years. The authors thank also I. Hénaut, A. Foissy, C. Filiatre, C. Buron for very helpful discussions, D. Lecerf and L. Picton for providing the polysaccharide sample and J. Kieffer $(S N F)$ for providing the synthetic copolymers.

\section{REFERENCES}

1 Goddard E.D., Ananthapadmanabhan K.P. (1993) Interactions of Surfactants with Polymers and Proteins, CRC Press, Boca Raton, FL.

2 Picullel L., Guillemet F., Thuresson K., Shubin V., Ericsson O. (1996) Adv. Colloid Interfac. 631.

3 Kwak J.C.T. (1998) Polymer-Surfactant Systems; Surfactant Science Series, Marcel Dekker, New York, Vol. 77.

4 Claesson P.M., Dedinaite A., Popotshoshev E. (2001) Physical Chemistry of Polyelectrolytes, Marcel Dekker, New-York, Vol. 99, p. 447

5 Taylor D.J.F., Thomas R.K., Penfold J. (2007) Adv. Colloid Interfac. 132, 69.

6 Goddard E.D. (2002) J. Colloid Interf. Sci. 256, 228 and references therein.

7 Nirmesh J., Trabelsi S., Guillot S., McLoughlin D., Langevin D., Letellier P., Turmine M. (2004) Langmuir 20, 8496.

8 Buron C., Filiatre C., Membrey F., Foissy A., Argillier J.-F. (2004) Colloid Polym. Sci. 282, 446.

9 Trabelsi S., Guillot S., Ritacco H., Boue F., Langevin D. (2007) Eur. Phys.J.E 23, 305.

10 von Klitzing R., Asnacios A., Langevin D. (2000) Colloid. Surface. A 167, 189.

11 Asnacios A., Langevin D., Argillier J.F. (1998) Eur. Phys. J. B 5, 905 .

12 McLoughlin D., Langevin D. (2004) Colloid. Surface. A 250, 79.

13 Monteux C., Williams C.E., Bergeron V. (2004) Langmuir 20, 5367.

14 Naves A.F., Petri D.F.S. (2005) Colloid. Surface. A 254, 207.

15 Proietti N., Amato M.E., Masci G., Segre A.L. (2002) Macromolecules 35, 4365.

16 Stubenrauch C., Albouy P.A., von Klitzing R., Langevin D. (2000) Langmuir 16, 3206.

17 Penfold J. (2002) Curr. Opin. Colloid Surf. 7, 139. Taylor D.J.F., Thomas R.K., Penfold J. (2002) Langmuir 18, 4784.

18 Staples E., Tucker I., Penfold J., Warren N., Thomas R.K., Taylor D.J.F. (2002) Langmuir 18, 5147.

19 Trabelsi S., Langevin D. (2007) Langmuir 23, 1248. 
20 Monteux C., Fuller G.G., Bergeron V. (2004) J. Phys. Chem. B 108, 16473.

21 Bergeron V., Langevin D., Asnacios A. (1996) Langmuir 12, 1550 .

22 Asnacios A., Langevin D., Argillier J.F. (1996) Macromolecules 29, 7412 .

23 Dubin P.L., Rigsbee D.R., Gan L.-M., Fallon A. (1988) Macromolecules 21, 2555.

24 Wang Y., Kimura K., Dubin P.L. (2000) Macromolecules 33, 3324 .
25 Bhattacharrya A., Monroy F., Langevin D., Argillier J.F. (2000) Langmuir 16, 8727.

26 IFP patent (2001) 01/14085.

27 Babak V.G., Vikohoreva G.A., Lukina I.G. (1997) Colloid. Surface. A 128, 74.

28 IFP patent (1996) 96/15822.

29 IFP patent (2001) 01/14816.

Final manuscript received in June 2009 Published online in October 2009 